\title{
Thermal properties of 3-D printed polylactic acid-metal composites
}

\author{
John Laureto ${ }^{1} \cdot$ Julie Tomasi $^{2} \cdot$ Julia A. King $^{2} \cdot$ Joshua M. Pearce $^{1,3}$
}

Received: 16 May 2016 / Accepted: 14 March 2017 / Published online: 12 April 2017

(c) Springer International Publishing Switzerland 2017

\begin{abstract}
Standard fused filament fabrication (FFF)based 3-D printers fabricate parts from thermopolymers, such as polylactic acid (PLA). A new range of metal based PLA composites are available providing a novel range of potential engineering materials for such 3-D printers. Currently, limited material data, specifically thermal property characterization is available on these composites. As a result, the application of these materials into functional engineered systems is not possible. This study aims to fill the knowledge gap by quantifying the thermal properties of copperFill, bronzeFill, magnetic iron PLA, and stainless steel PLA composites and provide insight into the technical considerations of FFF composite 3-D printing. Specifically, in this study the correlation of the composite microstructure and printing parameters are explored and the results of thermal conductivity analysis as a function of printed matrix properties are provided. Considering the relative deviation from the filament raw bulk analysis, the results show the printing operation significantly impacts the resultant component density. Experimentally collected thermal conductivity values, however, do not correlate to the theoretical models in the literature and more rigorous quantitative exercises are required to determine true percent porosity to accurately model the effect of air pore volume
\end{abstract}

Joshua M. Pearce

pearce@mtu.edu

1 Department of Materials Science and Engineering, Michigan

Technological University, 601 M\&M Building, 1400

Townsend Drive, Houghton, MI 49931-1295, USA

2 Department of Chemical Engineering, Michigan Technological University, Houghton, USA

3 Department of Electrical and Computer Engineering, Michigan Technological University, Houghton, USA fraction on thermal conductivity. Despite this limitation, the thermal conductivity values provided can be used to engineer thermal conductivity into 3-D printed parts with these PLA-based composites. Finally, several high-value applications of such 3-D printed materials that look metallic, but have low thermal conductivity are reviewed.

Keywords Additive manufacturing $\cdot 3$-D printing · Thermal conductivity · Polylactic acid · RepRap · Composite

\section{Introduction}

Adrian Bowyer's release of the open-source RepRap (selfReplicating Rapid prototyper) 3-D printer [1-3] greatly accelerated the adoption of 3-D printing [4]. Standard RepRap 3-D printers fabricate parts using fused filament fabrication (FFF) ${ }^{1}$ and such open-source designs now constitute the majority of deployed 3-D printers [5]. As the costs for RepRap components have dropped below \$500 [6] and high-quality commercial RepRaps can be purchase assembled for \$1000-2200 [7], the potential for decentralized manufacturing with 3-D printing both in the developing [8] and developed countries [9] is feasible. Such decentralized digital fabrication leads to radical reductions in the cost of printing low quantity speciality items [10]. For instance, small production runs are suited for 3-D printing; highly customizable objects [11], functional prototypes [12] and maintence/replacement components [13]. Previous studies have shown that such manufacturing not only allows

\footnotetext{
${ }^{1}$ FFF is material extrusion by ASTM Standard F2792-12a. It should be noted that FFF is the generalized non-trademarked equivalent of fused deposition modeling (FDM).
} 
Table 1 Supplier recommended printing parameters and basic material properties

\begin{tabular}{lllll}
\hline Filament & $\begin{array}{l}\text { Hot end tempera- } \\
\text { ture }\left({ }^{\circ} \mathrm{C}\right)\end{array}$ & $\begin{array}{l}\text { Bed temperature } \\
\left({ }^{\circ} \mathrm{C}\right)\end{array}$ & Print speed $(\mathrm{mm} / \mathrm{s})$ & $\begin{array}{l}\text { Density } \\
\left(\mathrm{g} / \mathrm{cm}^{3}\right)\end{array}$ \\
\hline CopperFill & $190-210$ & $55-60$ & 50 & 4.0 \\
BronzeFill & $195-220$ & $50-60$ & 50 & 3.9 \\
Magnetic iron PLA & $185-195$ & 50 & Not specified & 1.8 \\
Stainless steel PLA & $195-220$ & 50 & Not specified & 2.4 \\
\hline
\end{tabular}

for a lower cost of even simple products for the consumer [14], but a lower impact on the environment as well [15].

Conventional FFF 3-D printers printed in primarily hard thermopolymer of ABS (acrylonitrile butadiene styrene) and PLA (polylactic acid), however, there are many other materials available on the market for consumer FFF 3-D printing including nylon, polycarbonate, high-density polyethylene, high impact polystyrene. In addition, there are a number of new functional materials including glow in the dark, flexible (ninjaflex and semiflex and other elastomers), water soluble (PVA), electrically conductive PLA, HIPS, INVOA-1800, Laybrick, Laywoo-D3, copperFill, bronzeFill, magnetic iron PLA and stainless steel PLA.

One functionality is the use of metal/polymer matrix composites for thermal applications. For example, an iron/ nylon feed stock material, manufactured using FFF printing technology, has shown to be applicable to rapid tooling die inserts [12]. Thermal conductivity of the matrix was found to be proportional to that of the metal filler additive. Similarly, the implementation of iron powder into an ABS matrix will increase the glass transition temperature of the polymer base, thus decreasing the softening point of a potential injection molding material [16]. 3-D printed fabrication of metal/polymer composites has been shown to promote dimensional stability, while simultaneously reducing the cost of manufacturing as compared to conventional methods [17]. Enhanced thermal conductivity polymer/ metal composites have been proposed; hybrid filler [18], nanoporous particle embedding [19], polypropylene composite with graphite and carbon black [20] and polymeric composites utilized for heat dissipation, are expanding in many fields of engineering [21].

A new range of open metal based PLA composites have been introduced to the market, providing a new range of potential engineering materials. Currently, limited material data, specifically thermal property characterization is available. As a result, the application of these materials into functional engineered systems is not possible. This study aims to fill the gap by quantifying the thermal properties of copperFill, bronzeFill, magnetic iron PLA, and stainless steel PLA composites and provide insight into the technical considerations of FFF composite 3-D printing. Specifically, composite microstructure and correlation of printing parameters to resultant performance will be understood.
This paper describes the results of thermal conductivity analysis as a function of printed matrix properties.

\section{Methodology}

\subsection{Materials}

Four metal/polymer composites are analyzed: copperFill, bronzeFill, stainless steel PLA and magnetic iron PLA. ColorFabb (copperFill and bronzeFill) and ProtoPasta (stainless steel PLA and magnetic iron PLA) are the only major suppliers of these composite filament types. The composite filaments are blends of PLA/PHA with metal powder additives, e.g., copper, bronze, ferritic iron and stainless steel. Filament material for this analysis was obtained in $0.75 \mathrm{~kg}$ spools per standard packaging requirements of the respective vendors. Due to 3-D printer design, a nominal filament diameter of $2.85 \mathrm{~mm}$ (0.112 in $) \pm 0.05 \mathrm{~mm}$ ( $\pm 0.001 \mathrm{in})$ was selected for development. Further relevant technical material data, mechanical properties and supplier recommended printing parameters are described in Table 1 [22-25]. ColorFabb's technical data sheets indicate a maximum tensile strength of 25 and $30 \mathrm{MPa}$ for copperFill and bronzeFill, respectively. Furthermore, flexural strength and flexural modulus are reported as $40 \mathrm{MPa}$ and 7.0 $\mathrm{GPa}$ for copperFill and $40 \mathrm{MPa}$ and 9.0 GPa for bronzefill. ProtoPasta does not report mechanical property information, however, it would be expected that due to a similarity in formulation and material type the maximum tensile strength, flexural strength and flexural modulus relatively similar to ColorFabb's reported values. Moreover, manufacturing condition and/or processing methods are not reported on ColorFabb's technical data sheets. Thus, correlating processing parameters to these mechanical properties should be empirically determined relative to an operators manufacturing conditions.

\subsection{Fabrication}

The utilization of an open-source architecture allowed for rapid development of digital build files and physical samples. Applying the testing methodology described in ASTM F433, thermal conductivity samples were modeled in 
Table 2 Cura profiles utilized for manufacture of component samples

\begin{tabular}{lll}
\hline Quality & Layer height & 0.25 \\
& Shell thickness & 1 \\
Fill & Bottom/top thickness & 1 \\
& Fill density & 100 \\
Speed and temperature & Print speed $(\mathrm{mm} / \mathrm{s})$ & 50 \\
& Printing temperature $\left({ }^{\circ} \mathrm{C}\right)$ & 190 \\
Filament & Bed temperature $\left({ }^{\circ} \mathrm{C}\right)$ & 60 \\
& Filament diameter $(\mathrm{mm})$ & 2.85 \\
Machine & Flow $(\%)$ & 100 \\
\hline
\end{tabular}

OpenSCAD 2015.03. Dimensional requirements, as stated in ASTM F433, require symmetric cylinders produced to a diameter of $50.8 \mathrm{~mm}$ ( 2 in $) \pm 0.25 \mathrm{~mm}(0.010 \mathrm{in})$ and a thickness of 2.29-12.7 mm (0.090-0.50 in) [26].

Slicing, i.e., the digital fabrication of a volumetric shape into two-dimensional vectors paths, was performed with Cura 15.04.4 utilizing the supplier recommended parameter sets (summarized in Table 2) as a baseline. The parameters that determine slicing conditions were developed in effort to produce $100 \%$ dense samples. Thus, effective 'fill' stripe, 'contour' offset alignment, extrusion temperature and flow percentage were critical. However, during initial parameter development understanding the space void between each vector path is difficult to quantify without further analysis $[27,28]$. Therefore, fabricated samples were expected to contain microscopic air voids. The resultant Cura profiles for the quantitative parameter development are displayed in Table 2.

A single Lulzbot TAZ 3.0 printer coupled with a $0.5 \mathrm{~mm}$ diameter extruder nozzle was employed. Use of a single printer removes variability observed in FFF 3-D printers [27]. A Budaschnozzle 2.0 extruder modification was required as the standard $3.0 \mathrm{~mm}$ polytetrafluoroethylene (PTFE) filament guide required an increase of $0.5 \mathrm{~mm}$ to account for excessive dimensional expansion of metal/polymer composite flow through the hot end. One print cycle/ build yielded four composite samples. Four samples provided adequate statistical relevance to the analysis while minimizing material waste. The printing systems utilized a singled extruder nozzle/head. Thus, four distinct build set-ups were required as described in Table 1 . The build platform/surface was prepared with a mechanical cleaning operation prior to each print cycle.

\subsection{Characterization}

Printed component fracture surfaces, transverse to the build orientation were imaged using a Philips XL 40 Environmental Scanning Electron Microscope (ESEM) for qualitative elemental analysis and back-scattered electron imaging. ESEM fracture surfaces provide information on metallic particle morphology that optical microscopy cannot. Captured back-scattered electron images highlight average atomic number of matrix constituents, thus providing a qualitative elemental analysis. Excessive charge build up on the sample as a result of the PLA constituent affected the SEM-BSE (scanning electron microscope back-scattered electron) images. Thus a low vacuum water atmosphere was required for analysis. The low vacuum mode limited the available incident $\mathrm{keV}$ from the electron source. As a result of this limiting condition, elemental mapping with EDS (energy dispersive spectroscopy) proved to be inadequate.

ImageJ 1.49 software was used for the conversion of SEM-BSE micrographs into an 8-bit image files [29]. From the converted image, a binary representation is created and a relative percentage of 'white' vs. 'black' is formulated allowing for volume percentages to be measured (it should be noted this method will underestimate sizes). By comparison, weight percentage is calculable from an Archimedes density analysis. Equation (1) equates a relationship between dry sample weight and wet sample weight to yield a density analysis that measures apparent porosity within the metal polymer matrix [30].

$\rho_{\mathrm{S}}=\frac{A}{A-B} \rho_{\mathrm{L}}$

where $\rho_{\mathrm{S}}$ density of solid body, $A$ weight of solid body in air, $B$ weight of solid body when immersed in test liquid, $\rho_{\mathrm{L}}$ density of test liquid at a given temperature $T$.

Thermal conductivity measurements of the printed materials utilized the guarded heat flow method of ASTM F433 using a Holometrix TCA300 Through-Plane Thermal Conductivity Tester. Prior to each analysis thermal paste, Dow Corning (Dow Dupont) 340 silicon heat sink compound, was applied to each sample [31]. Thermal conductivity measurements were taken at $55^{\circ} \mathrm{C}$ providing a temperature measurable near ambient while also producing a sufficient temperature gradient within the Holometrix TCA300 [32]. The heat flow through a disk specimen between two solid flat surfaces is modeled to measure thermal conductivity by Eq. (2) [26].

$k=\frac{q}{A} \frac{\Delta x}{\Delta T} t(\mathrm{~W} / \mathrm{m} \cdot \mathrm{K})$

where $k$ thermal conductivity of the sample $(\mathrm{W} / \mathrm{m} \mathrm{K}), q$ heat flow through sample (W), A cross-sectional area of the sample $\left(\mathrm{m}^{2}\right), \Delta x$ sample thickness $(\mathrm{m}), \Delta T$ temperature difference across the sample $\left({ }^{\circ} \mathrm{C}\right)$.

Printed virgin PLA material set the baseline for this analysis. Measurements allowed for identification of net percent increase of thermal conductivity as a result of 
Fig. 1 Generalized Vol. \% metallic filler addition effect on thermal conductivity

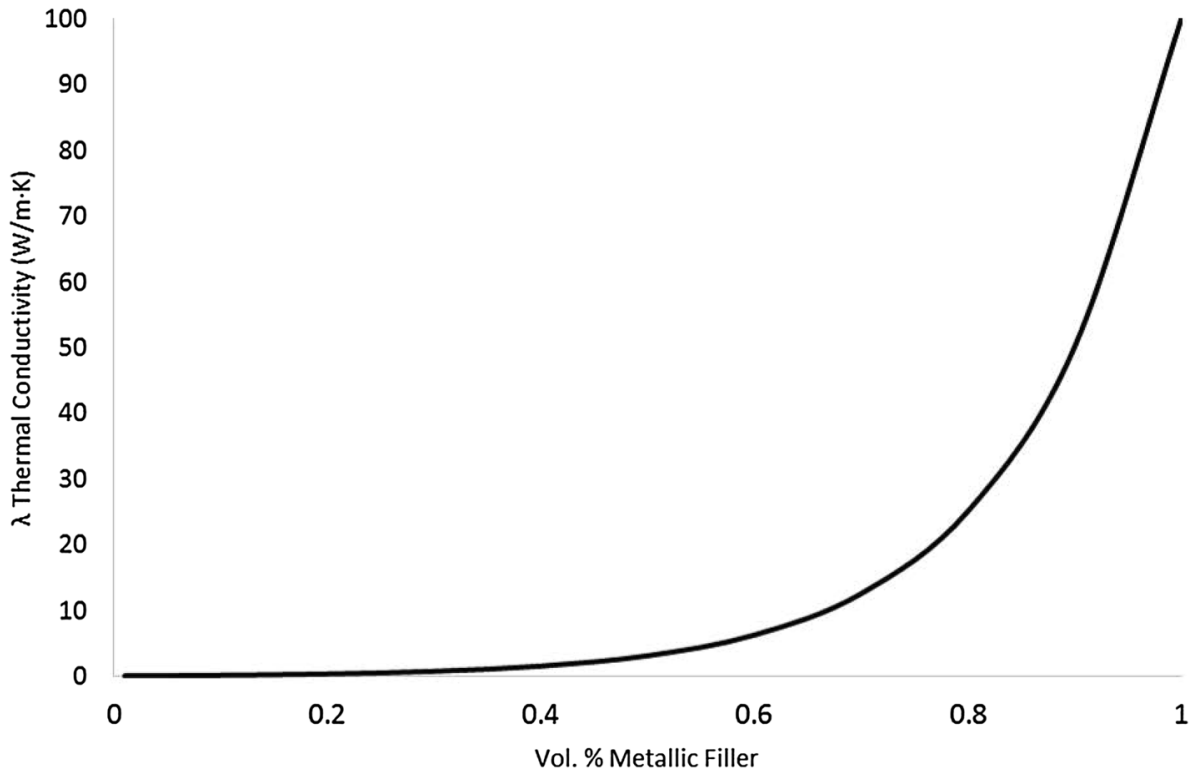

the printing operation and/or addition of metallic filler materials.

Thermal conductivity of two-phase systems can be modeled using the individual phases' thermal conductivity. Relative volume percentages, as determined from prior analysis, allow the calculation of a composite thermal conductivity. In the proposed system, the spatial distribution of respective metallic particles in uncontrolled. Thus, the thermal conductivity model does not take into account morphogical characteristics of the metallic fillers materials. The volume concentration dependency on bulk thermal conductivity of a two-phase system, as described by Mamunya [33], follows Lichtenecker's equations. The following Eq. (3) describes such a system where $\lambda_{\text {PLA }}$ and $\lambda_{\text {METAL }}$ correspond to the respective thermal conductivity of the PLA and metallic constituent, respectively.

$$
\begin{aligned}
\lambda= & \lambda_{\mathrm{PLA}}^{(1-\varphi)} \lambda_{\mathrm{METAL}}^{\varphi}-\text { equivalently }-\log \lambda=\log \lambda_{\mathrm{PLA}} \\
& +\left(\log \lambda_{\mathrm{METAL}}-\log \lambda_{\mathrm{PLA}}\right) \varphi
\end{aligned}
$$

where $\lambda$ composite thermal conductivity $(\mathrm{W} / \mathrm{m} \mathrm{K})$, $\lambda_{\text {PLA }}$ polymer constituent thermal conductivity $(\mathrm{W} / \mathrm{m} \mathrm{K})$,

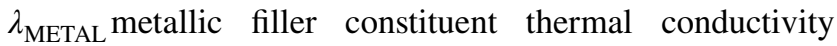
$(\mathrm{W} / \mathrm{m} \mathrm{K}), \varphi$ volume concentration of metallic filler $(\%)$.

Lichtenecker's dependence does not take into account the percolation theory. Two-phase modeling need not accommodate the percolation theory where thermal conductivity ratios of 1 to $10^{3}$ are witnessed [33]. Thus, metallic filler particles are independent of its nearest neighbor, i.e., no continuous conductive flow paths are readily available in these analysis.

The Holmetrix TCA300 analyzed the generated sample medium with each FFF layer parallel to one another.
Specifically, due to the layer-wise fashion of the manufacturing process the thermal conductivity measurements are a prediction of the series interaction of each flow through every layer. As described by Agarwala, layering effects of the printing process develop compounding un-intentional pore formation [34]. Pore phases (porosity constituents) are effectively thermal insulators. Pore thermal conductivity and pore volume fractions less than $15 \%$, of the bulk composite matrix are defined by Eq. (4), the Maxwell-Eucken bound [35].

$\lambda_{\text {SMITH }}=\lambda_{\text {METAL }} \frac{\lambda_{\text {PLA }}+2 \lambda_{\text {METAL }}+2 v_{\text {PORE }}\left(\lambda_{\text {PLA }}-\lambda_{\text {METAl }}\right)}{\lambda_{\text {PLA }}+2 \lambda_{\text {METAL }}-2 v_{\text {PORE }}\left(\lambda_{\text {PLA }}-\lambda_{\text {METAl }}\right)}$

where $\lambda_{\text {SMITH }}$ Smith corrected thermal conductivity $(\mathrm{W} / \mathrm{m}$ $\mathrm{K}), \lambda_{\text {PLA }}$ polymer constituent thermal conductivity $(\mathrm{W} / \mathrm{m}$ $\mathrm{K}), \lambda_{\text {METAL }}$ metallic filler constituent thermal conductivity $(\mathrm{W} / \mathrm{m} \mathrm{K}), v_{\mathrm{PORE}}$ volume concentration of air void (\%).

Generalized models for metallic filler dependency [Eq. (3)] on thermal conductivity and degradation of that value due to porosity [Eq. (4)] are shown in Figs. 1 and 2, respectively. Generated plots are shown with $\lambda_{\mathrm{PLA}}=0.1$ and $\lambda_{\text {METAL }}=10^{2}$ for comparison.

\section{Results}

\subsection{Density and constituent $\mathrm{Wt} / \mathrm{Vol}$ percentage determination}

The Archimedes density analysis displayed variation in apparent densities ( $\mathrm{g} / \mathrm{cc}$ ) from part to part relative to each material. Statistical analysis including standard deviation and $95 \%$ confidence intervals confirm valid measurements. 
Fig. 2 Generalized Vol. \% Air void effect on thermal conductivity
Table 3 Measured density of filament materials utilizing archimedes method

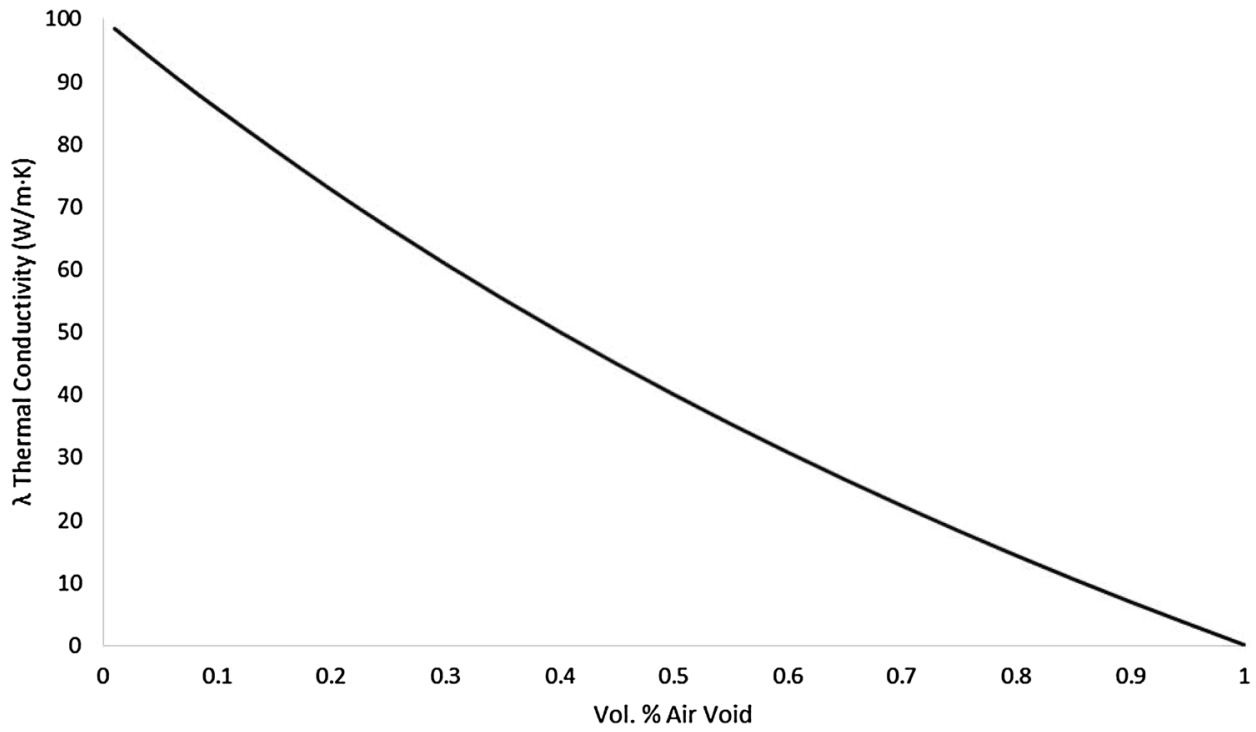

\begin{tabular}{lllllll}
\hline Material & ID & Dry mass $(\mathrm{g})$ & Wet mass $(\mathrm{g})$ & $\rho \mathrm{H}_{2} \mathrm{O}(\mathrm{g} / \mathrm{ml})$ & $\begin{array}{l}\rho \text { of raw fila- } \\
\text { ment }\left(\mathrm{g} / \mathrm{cm}^{3}\right)\end{array}$ & $\begin{array}{l}\rho \text { of printed } \\
\text { body }(\mathrm{g} / \\
\left.\mathrm{cm}^{3}\right)\end{array}$ \\
\hline CopperFill & 1 & 20.4054 & 14.0309 & 0.9978 & 3.5297 & 3.1941 \\
& 2 & 21.2323 & 14.9753 & 0.9978 & 3.4390 & 3.3859 \\
& 3 & 20.3595 & 14.0442 & 0.9978 & 3.4773 & 3.2167 \\
BronzeFill & 4 & 20.5622 & 14.1454 & 0.9978 & 3.4368 & 3.1974 \\
& 1 & 23.0749 & 16.8048 & 0.9987 & 3.5996 & 3.6754 \\
& 2 & 23.0788 & 16.7940 & 0.9987 & 3.6009 & 3.6674 \\
Magnetic iron PLA & 1 & 12.4936 & 6.2290 & 0.9978 & 1.8689 & 1.9899 \\
& 3 & 22.9777 & 16.4980 & 0.9987 & 3.6474 & 3.5415 \\
& 4 & 23.5184 & 17.2299 & 0.9987 & 3.4836 & 3.7350 \\
& 3 & 12.4908 & 6.1984 & 0.9978 & 1.8863 & 1.9807 \\
Stainless steel PLA & 12.5557 & 6.2534 & 0.9978 & 1.9441 & 1.9879 \\
& 4 & 12.4839 & 6.2093 & 0.9978 & 1.9025 & 1.9852 \\
& 2 & 15.3457 & 8.8181 & 0.9978 & 2.1862 & 2.3457 \\
& 3 & 15.2725 & 8.6856 & 0.9978 & 2.2037 & 2.3135 \\
& 4 & 15.2467 & 8.7468 & 0.9978 & 2.2971 & 2.3405 \\
\hline
\end{tabular}

Table 3 summarizes the resultant printed density, weight percent, and volume percent for each copperFill, bronzeFill, stainless steel PLA, magnetic iron PLA, and virgin PLA sample. Calculations described in Eqs. (5) and (6) allow for the value determination shown in Table 3 [30]. Table 4 describes the statistical analysis of the measured values indicated.

$\mathrm{Wt} \%_{\text {METAL }}=\frac{\left(\frac{1}{\rho_{\text {PRINTBODY }}}\right)-\left(\frac{1}{\rho_{\mathrm{PLA}}}\right)}{\left(\frac{1}{\rho_{\text {METAL }}}\right)-\left(\frac{1}{\rho_{\mathrm{PLA}}}\right)}$
Vol $\%_{\text {METAL }}=\frac{\frac{M_{\mathrm{s}}\left(W t \%_{\mathrm{METAL}}\right)}{\rho_{\text {METAL }}}}{\frac{M_{\mathrm{S}}}{\rho_{\mathrm{S}}}}$

where $M_{\mathrm{S}}$ dry mass of solid component $(\mathrm{g}), \rho_{\mathrm{S}}$ density of solid composite $(\mathrm{g} / \mathrm{ml})$.

CopperFill values exhibit the greatest deviation in printed density values relative to its bulk density. Approximated by Eq. (7), an average (-)6.61\% drop in density is measured between bulk and printed samples. Conversely, 
Table 4 Statistical analysis of measured raw and printed body density

\begin{tabular}{llllllc}
\hline Material & $\begin{array}{l}\text { Avg. raw } \\
\text { filament } \rho(\mathrm{g} / \\
\left.\mathrm{cm}^{3}\right)\end{array}$ & Std. dev 95\% CI & $\begin{array}{l}\text { Avg. printed } \\
\text { body } \rho(\mathrm{g} / \\
\left.\mathrm{cm}^{3}\right)\end{array}$ & Std. dev $95 \% \mathrm{Cl}$ \\
\hline CopperFill & 3.4707 & 0.0435 & $3.4015-3.5399$ & 3.2485 & 0.0921 & $3.1019-3.3951$ \\
BronzeFill & 3.5829 & 0.0698 & $3.4718-3.6940$ & 3.6548 & 0.0814 & $3.5254-3.7843$ \\
Magnetic iron PLA & 1.9005 & 0.0322 & $1.8493-1.9516$ & 1.9859 & 0.0040 & $1.97958-1.99227$ \\
Stainless steel PLA & 2.2269 & 0.04489 & $2.1491-2.3047$ & 2.3261 & 0.0201 & $2.2940-2.3581$ \\
\hline
\end{tabular}

bronzeFill, stainless steel PLA and magnetic iron PLA measure a net increase in density after printing; $(+) 1.99 \%$, $(+) 4.40 \%$ and $(+) 4.36 \%$, respectively. Raw (i.e., virgin) printer filament was utilized as the bulk density. The measured net increase in relative density and/or mass gain within a specific volume indicates that the printing process increased the density of the composite material during the extrusion process.

$\%$ Variance $=\frac{\left(\rho_{\text {PRINTBODY }}\right)-\left(\rho_{\text {BULK }}\right)}{\left(\frac{\rho_{\text {PRINTBDY }}+\rho_{\text {BULK }}}{2}\right)}(100)$

Scanning electron microscopy confirms and elaborates on the findings of the Archimedean analysis. Representative SEM micrographs of copperFill, bronzeFill, magnetic iron PLA, stainless steel PLA and virgin PLA are displayed in Figs. 3, 4, 5, 6 and 7. Overlaid arrows indicated build direction on each respective SEM micrograph. Layer lines, resultant of multilayered printing, are abundant. Triangular shaped air voids are visible and distinguishable from the matrix as a result of their non-spherical morphology caused by oblong cross-sectional layers being deposited side by side. Combining area percent analysis to the Archimedean density shows CopperFill is the most porous of all manufactured samples.

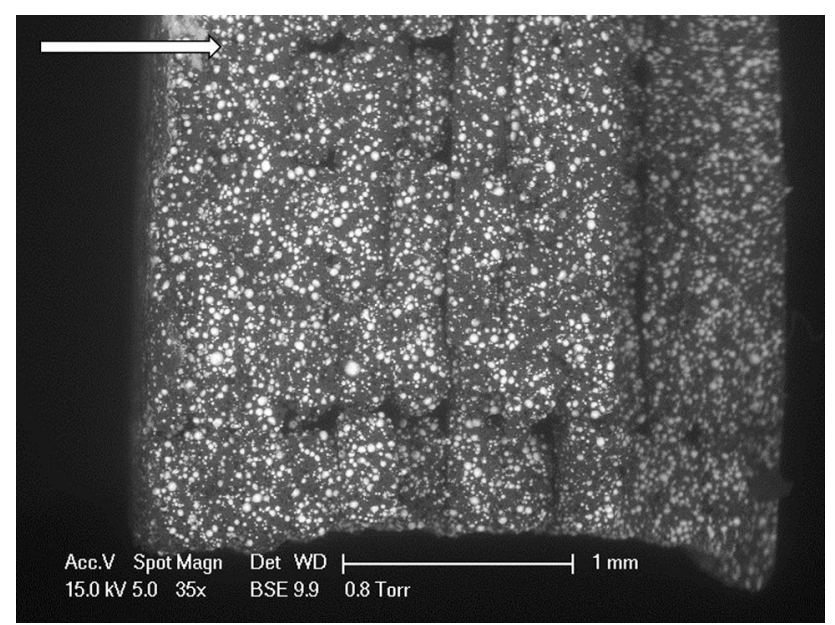

Fig. 3 SEM-BSE image of copperFill cross-section

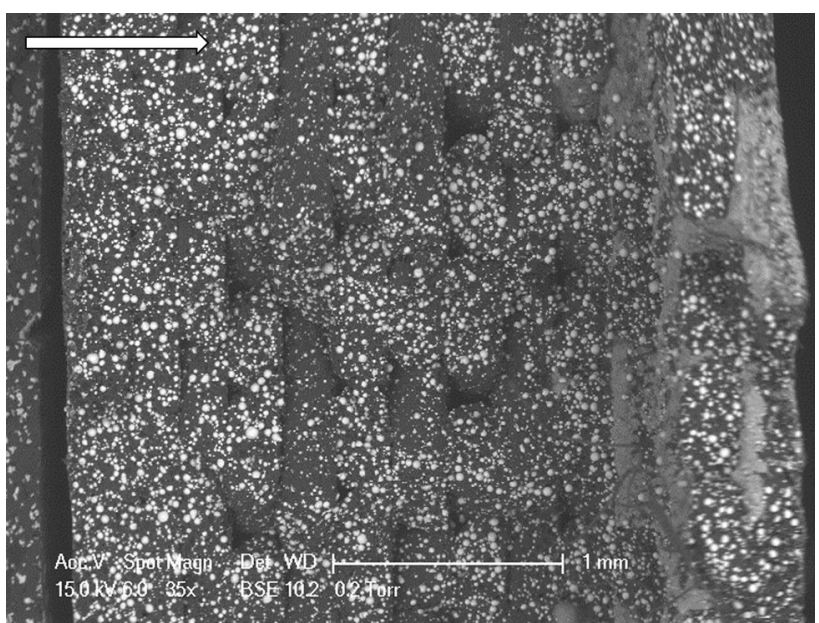

Fig. 4 SEM-BSE image of bronzeFill cross-section

Figure 8 shows a sample analysis from ImageJ for CopperFill. In this analysis, air voids correlate to the white fields displayed and represent $5.636 \%$ of the available cross section.

Conversely, air voids are apparent within the matrix for bronzeFill, magnetic iron PLA and stainless steel PLA. These results are not in agreement with the aforementioned

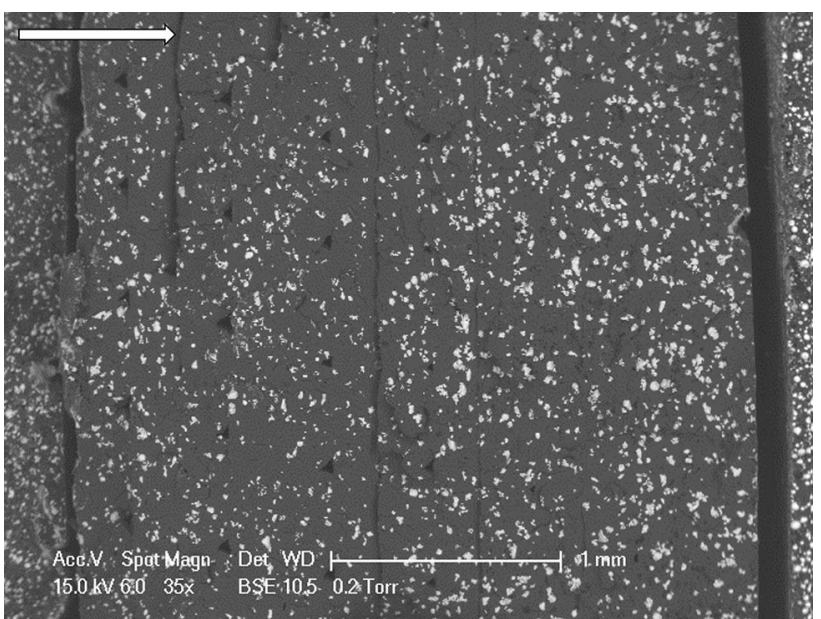

Fig. 5 SEM-BSE image of magnetic iron PLA cross-section 


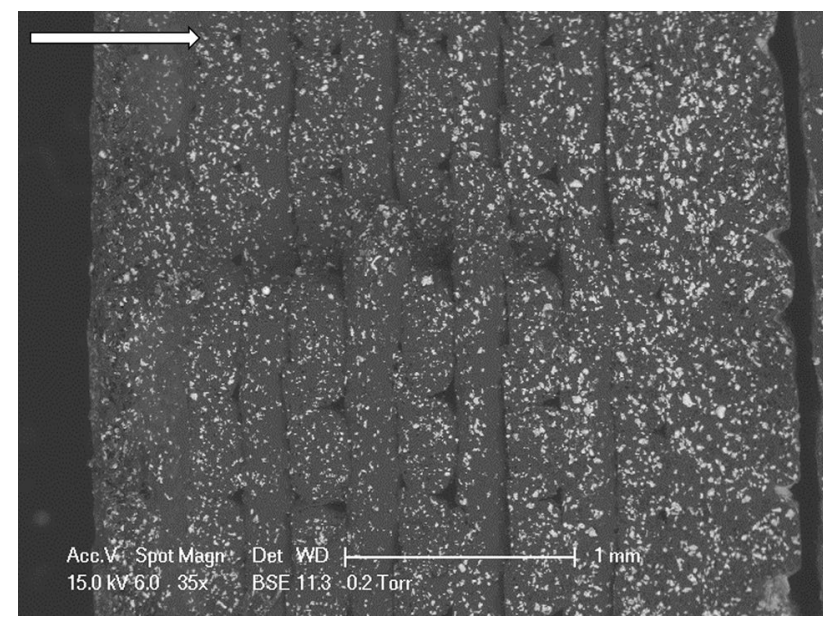

Fig. 6 SEM-BSE image of stainless steel PLA cross-section

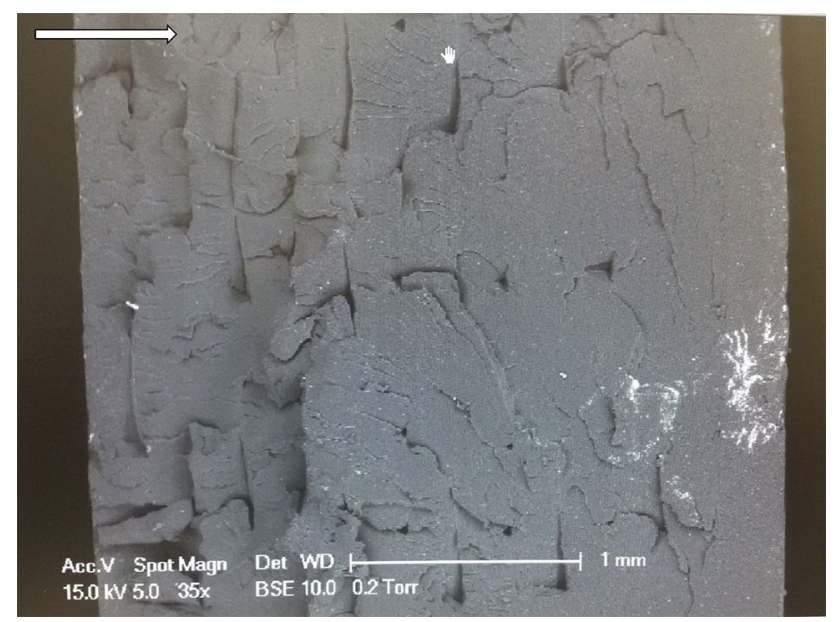

Fig. 7 SEM-BSE image of virgin PLA cross-section
Archimedean density analysis, as all printed components appear to exhibit extrinsic porosity as a result of printing. These occurrences are likely due to experimental process error. There is inadequate characterization of apparent air void fraction through bulk raw filament density assumptions and raw filament buoyancy forces. Specifically, the air void fraction was determined by comparing the bulk raw filament Archimedes density to that of the composite printed sample. Archimedean density analysis was selected as an adequate method as there are no other ideal methods to determine density of an irregularly shaped object. Furthermore, the bulk raw filament density determined was assumed $100 \%$ dense during comparison. The result bulk density assumption, in addition to potential and unaccounted for significant buoyancy forces of the filament sample potentially lead to the mis-representation of material density in the Archimedean analysis. Thus, a more accurate demonstration of the pore fraction was performed with ImageJ 1.49 as the weight of the sample in water [Eq. (1)] was not taken into consideration with this method [29]. Results of this study, and their respective deviation from the Archimedes analysis are shown in Table 5.

\subsection{Particle size determination}

Back-scattered electron (BSE) images can also provide a qualitative analysis of the 'microstructure'. Visible particle morphology of the metallic filler material are spherical for copperFill and bronzeFill. Conversely, stainless steel PLA and magnetic iron PLA contain 'flake' like particles. ImageJ coupled with the BSE image allowed for the particle size determination. CopperFill and bronzeFill were assumed spherical based upon the morphology shown in Fig. 9a, while stainless steel and magnetic iron PLA are flake like as shown in Fig. $9 \mathrm{~b}$.

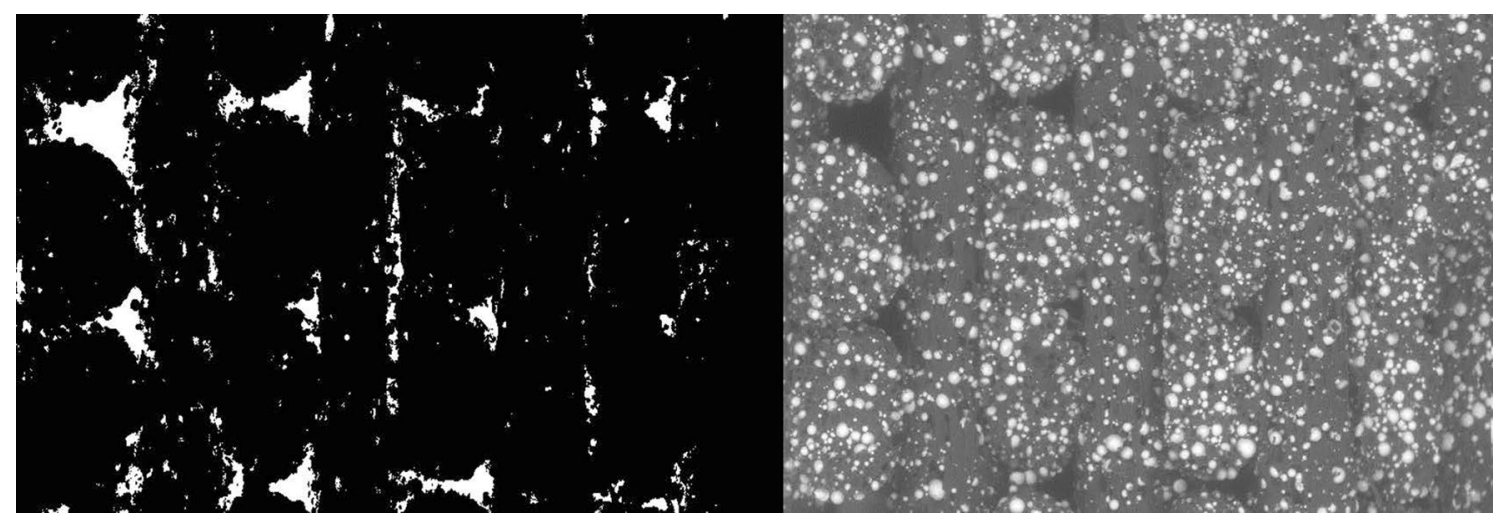

Fig. 8 Image 1.49 Analysis of air void fraction in copperFill. Threshold corrections have been performed, so the representative scale bar has been removed for precise quantitative measurement 
Table 5 Average Vol. \% determination of polymer metal matrix constituents after printing

\begin{tabular}{lllllllll}
\hline & \multicolumn{3}{l}{ Archimedean method } & & \multicolumn{3}{l}{ ImageJ method } \\
\cline { 2 - 3 } & Vol. \% metallic & Vol. \% PLA & Vol. \% air & & Vol. \% metallic & Vol. \% PLA & Vol. \% air \\
\hline CopperFill & 26.10 & 67.52 & 6.37 & 40.19 & 54.17 & 5.63 \\
BronzeFill & 32.38 & 67.61 & - & 38.06 & 58.74 & 3.19 \\
Magnetic iron PLA & 11.32 & 88.67 & - & & 13.67 & 83.57 & 2.75 \\
Stainless steel PLA & 16.08 & 83.91 & - & & 17.25 & 80.39 & 2.34 \\
\hline
\end{tabular}

- means not measured
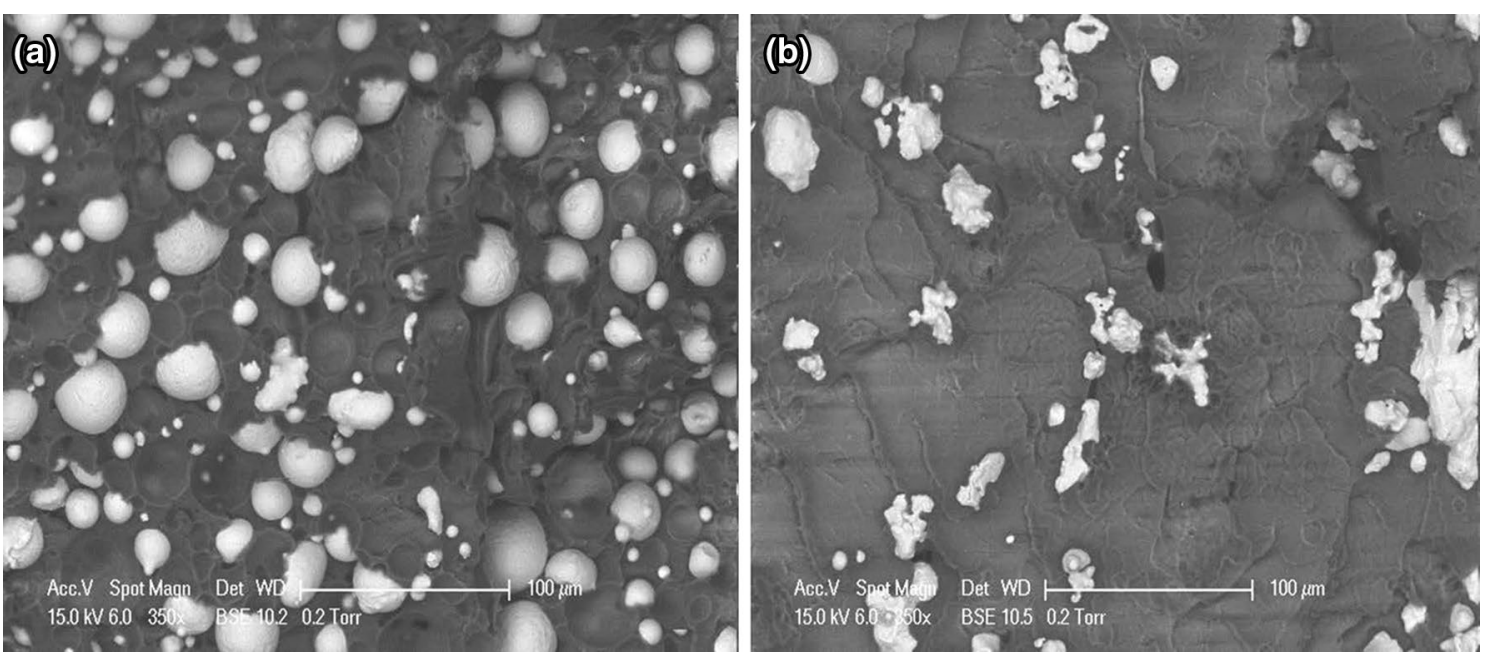

Fig. 9 a Representative morphology of spherical particles (CopperFill and BronzeFill), b representative morphology of lake particles (magnetic iron PLA and stainless steel PLA)

Thus, extracted particle area measurement determination, in Image J 1.49, was converted to diameter through a common area equation calculation $\left(\pi r^{2}\right)$. While the 'flake' like metallic particles of stainless steel PLA and magnetic iron PLA were analyzed using an average Feret diameter. The particle size distribution analysis is represented in Figs. 10, 11, 12 and 13.

\subsection{Composite thermal conductivity (W/mk) determination}

The measured thermal conductivity for the studied open metal/PLA composites is shown in Fig. 14. The solid lines in these figures correlate to the prescribed relationships of Eq. (4) with $10^{3}, 10^{2}$, and $10^{1}$ constituent thermal conductivity ratios $\left(\lambda_{\mathrm{METAL}} / \lambda_{\mathrm{PLA}}\right)$.

Experimentally collected thermal conductivity values do not correlate to the prescribed models shown by Lichtenecker and Smith. Generalized modeled and quantitative thermal conductivity presented prior (Fig. 14) are further developed in Table 6. Selected metallic constituent thermal conductivity values, shown in Table 6 , represent corresponding magnitudes of the metallic filler component.
Thus, the values presented are to be considered reference and may vary depending upon chemistry (i.e., purity and alloy of the respective constituent).

Significant deviation is notable from the analysis with exception to stainless steel PLA. The calculated $\lambda_{\text {SMITH }}$ value for copperFill, bronzeFill and magnetic iron PLA vary, relative to the measured thermal conductivity by Holometrix TCA 300 by $(+) 157.29,(+) 93.03$ and (+)33.18\%, respectively. Conversely, measured values for stainless steel PLA deviate by $4.17 \%$. The largest variance presents in metal/polymer composites where the metallic constituent thermal conductivity is $10^{3}$ times greater than the polymer constituent. Comparing base PLA, 0.1849 W/m K, to measured values implies that there is greater dependence on apparent print density than thermal conductivity of each respective constituent. Specifically, BronzeFill outperforms CopperFill by $21.92 \%$ even though the metal thermal conductivities are 50 and $380 \mathrm{~W} / \mathrm{m} \mathrm{K}$, respectively. Conversely, Magnetic Iron PLA outperforms Stainless Steel PLA where the metal thermal conductivities are 79.5 vs. $18 \mathrm{~W} / \mathrm{m} \mathrm{K}$, and metallic filler volume percentages are 13.37 and $17.25 \%$, respectively.

Developed models for porosity considerations assume cylindrical obstacles (pores) dispersed uniformly within 
Fig. 10 CopperFill particle size $(\mu \mathrm{m})$ distribution
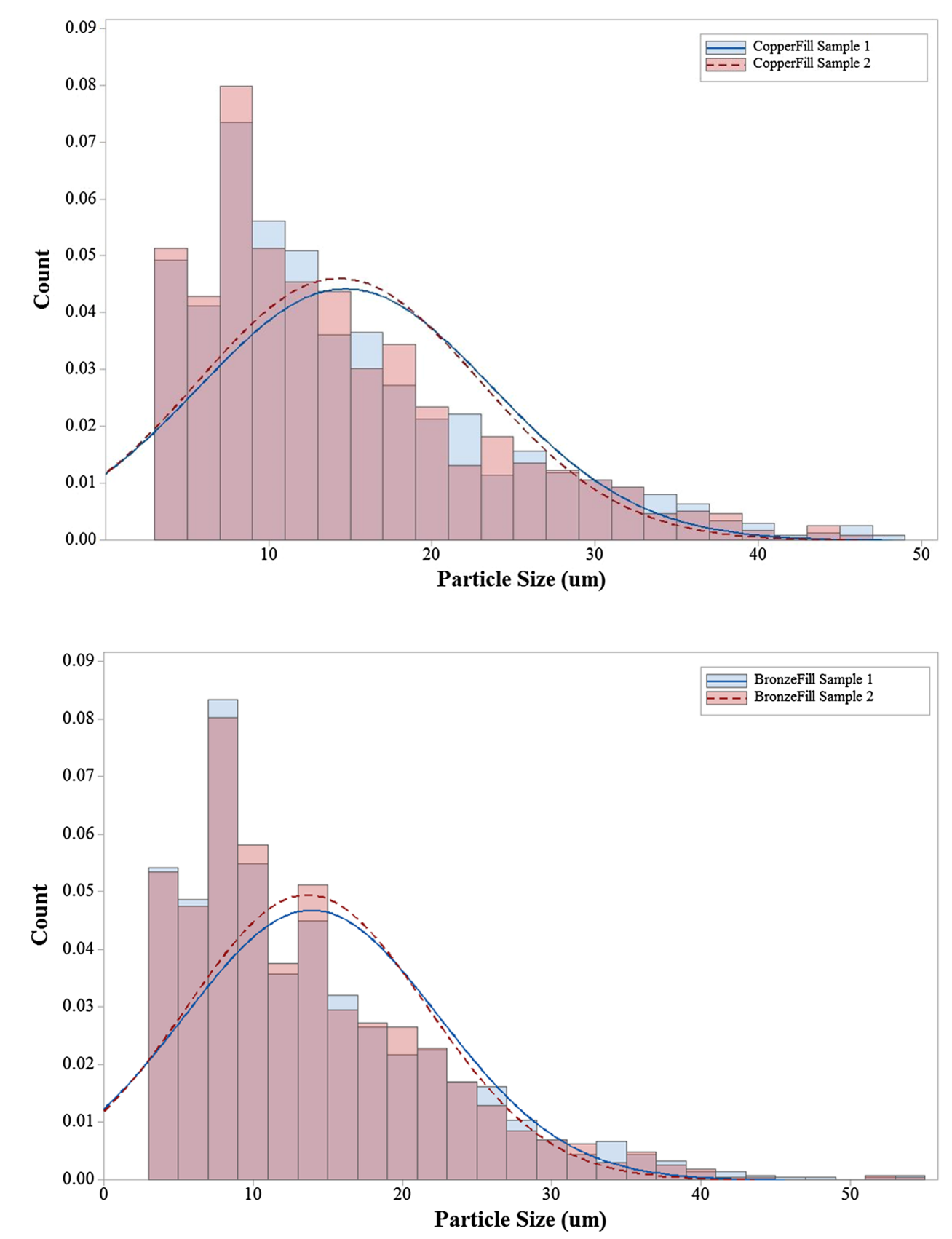

Fig. 11 BronzeFill particle size $(\mu \mathrm{m})$ distribution the metal/polymer matrix. Other methods, described by Smith, include open porosity considerations more readily suited to fit the developed samples [35]. The realized cross-sectional geometry, described in Figs. 3, 4, 5, 6 and 7 indicate the presence of non-equiaxed open pores which are more readily suited by Landauer's relation to percolation theory. Landauer's theory assumes pore zones to be equally dispersed throughout the matrix with respect to the input heat [36]. These concepts apply to the developed samples due to printer type and layer base manufacturing methods. In effect, an assumption can be made that each build layer contains equivalently randomly orientated air pore structures. Application of the modeled, described in Eq. (8) yields the following results displayed in Table 7.

$$
\begin{aligned}
\lambda_{\text {Landauer }}= & \frac{1}{4}\left\{\left(3 v_{\mathrm{C}}-1\right) \lambda_{\mathrm{C}}+\left(3 v_{\mathrm{A}}-1\right) \lambda_{\mathrm{A}}+\left(\left(3 v_{\mathrm{C}}-1\right) \lambda_{\mathrm{C}}\right.\right. \\
& \left.\left.+\left(3 v_{\mathrm{A}}-1\right) \lambda_{\mathrm{A}}\right)^{2}+8 \lambda_{\mathrm{C}} \lambda_{\mathrm{A}}{ }^{1 / 2}\right\}
\end{aligned}
$$

where $\lambda_{\text {Landauer }}$ Landauer corrected thermal conductivity, $v_{\mathrm{C}}$ Vol. \% composite (copperFill, bronzeFill, magnetic iron PLA, stainless steel PLA), $v_{\mathrm{A}}$ Vol. $\%$ air void, $\lambda_{\mathrm{C}}$ measured thermal conductivity of composite $(\mathrm{W} / \mathrm{m} \mathrm{K}), \lambda_{\mathrm{A}}$ standard value for the thermal conductivity of air $(\mathrm{W} / \mathrm{m} \mathrm{K})$. 
Fig. 12 Magnetic iron PLA feret diameter ( $\mu$ um) distribution

Fig. 13 Stainless steel PLA feret diameter $(\mu \mathrm{m})$ distribution
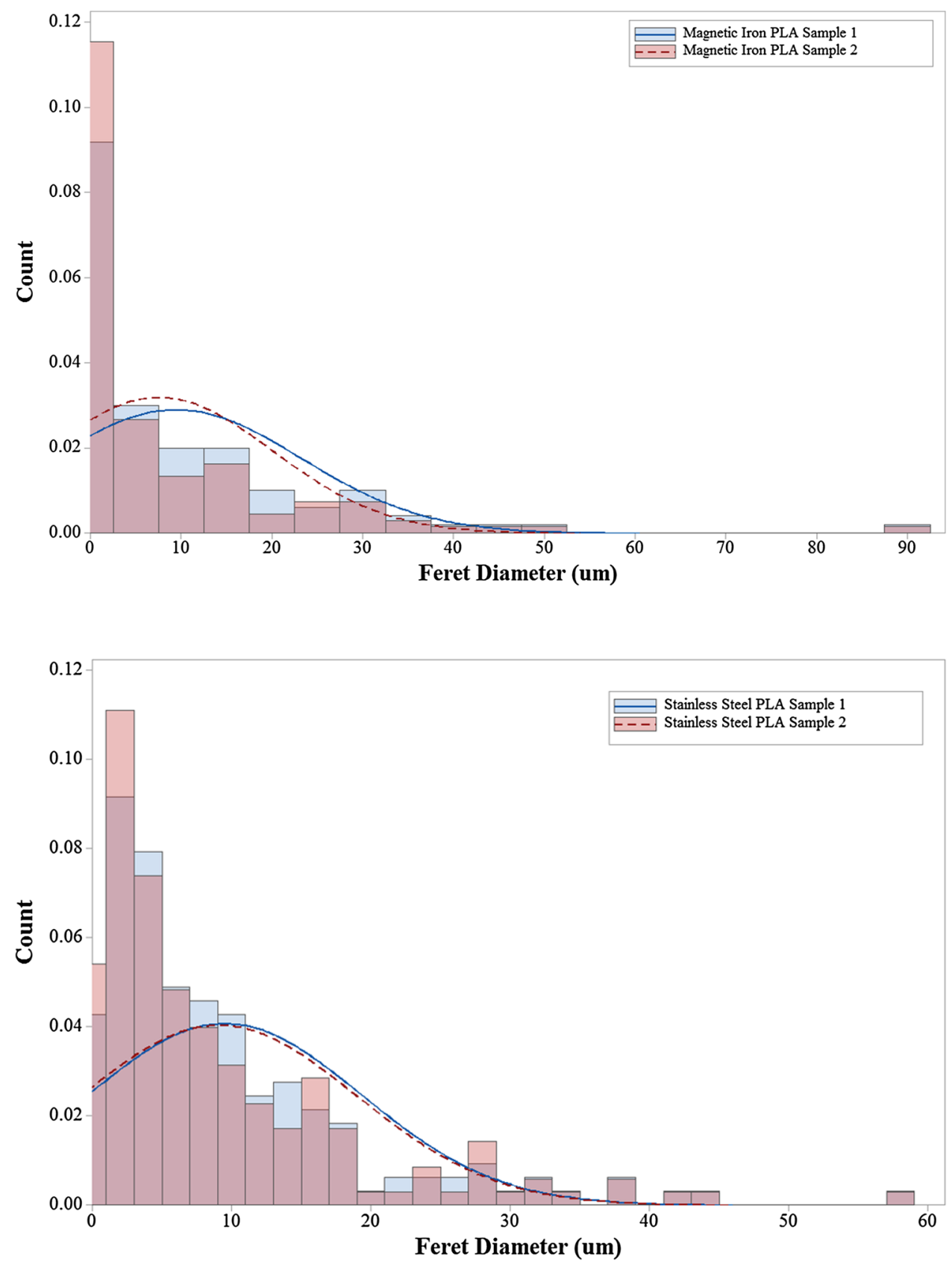

It is clear that the existing models are deficient in fitting the experimental data.

\section{Discussion}

More rigorous quantitative exercises are required to determine true percent porosity to accurately model the effect of air pore volume fraction on thermal conductivity. In effect, low pore volume fraction $(<6 \%)$ does not model the system accurately.
Specifically, Smith and Landauer models are expected to model the system appropriate assuming appropriate volume fraction determination. Tsotsas et al. compiled multiple analytical approach methods for thermal conductivity determination of gas-filled packed beds [37]. Moreover, the layer based manufacturing methods induce porosity formation layer-by-layer and by each subsequent pass of the hot end compounds the development of air voids. The models utilized may not adequately represent the geometry of the air void fraction. Thus, the assumption of non-equiaxed pores is insufficient at modeling printed components. More likely, however, is the presence of micron size "layers" 


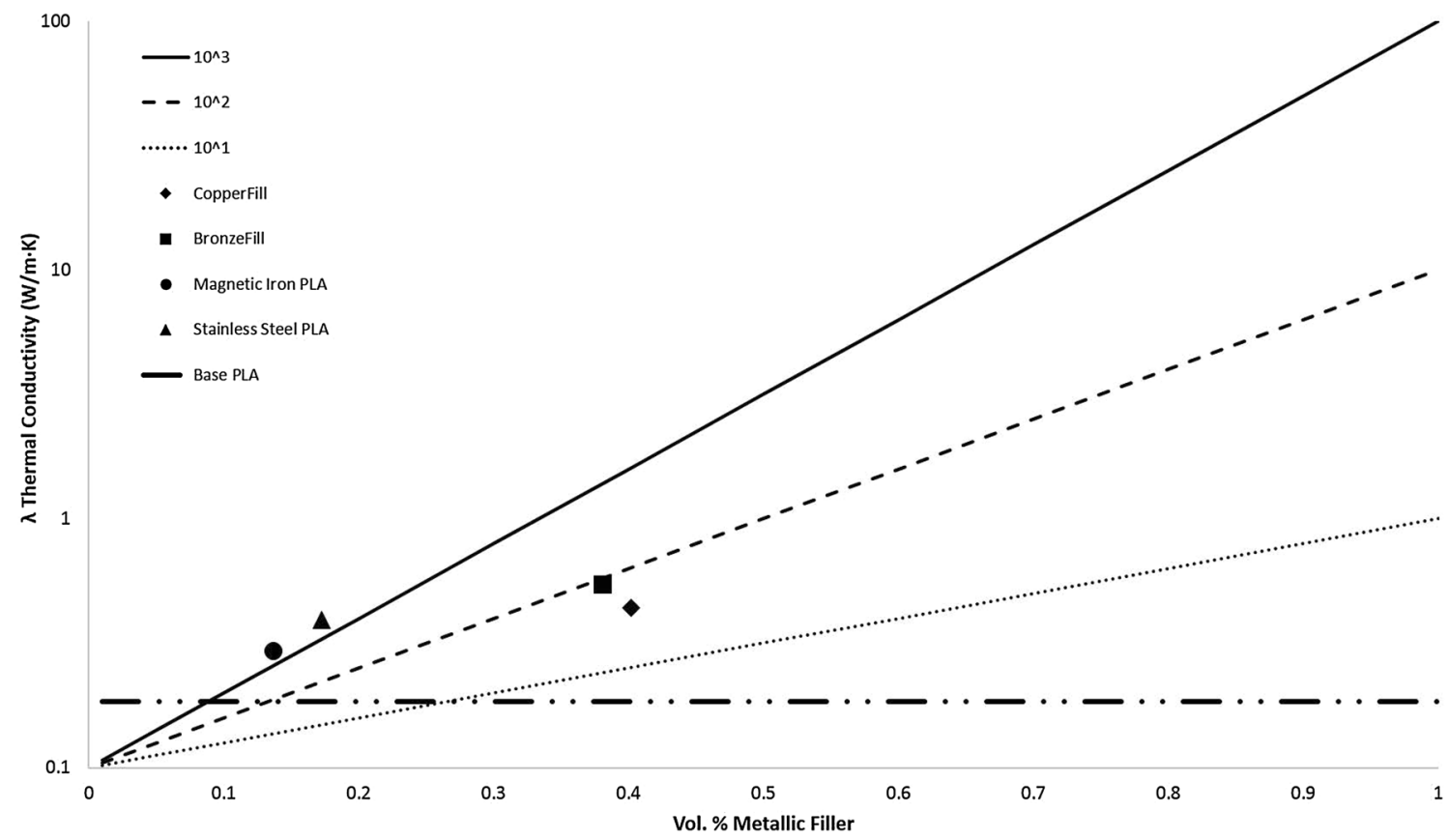

Fig. 14 Resultant thermal conductivity measurements utilizing Holometrix TCA300 compared to Lichtenecker's dependence [Eq. (4)]

Table 6 Measured thermal conductivity of copperFill, bronzeFill, magnetic iron PLA and stainless steel PLA compared to Lichtenecker model, Smith air void correction and base PLA

\begin{tabular}{|c|c|c|c|c|c|c|}
\hline Sample material & $\begin{array}{l}\text { Average Holome- } \\
\text { trix TCA } 300 \lambda_{\mathrm{s}} \\
(\mathrm{W} / \mathrm{m} \mathrm{K})\end{array}$ & $\begin{array}{l}\text { Lichtenecker } \\
\text { prediction }[\mathrm{Eq} . \\
(4)] \lambda_{\text {Lichtenecker }} \\
(\mathrm{W} / \mathrm{m} \mathrm{K})\end{array}$ & $\begin{array}{l}\text { Lichtenecker } \\
\text { deviation } \% \text { from } \\
\text { measured } \lambda_{\mathrm{s}}\end{array}$ & $\begin{array}{l}\text { Smith air void cor- } \\
\text { rection }[\mathrm{Eq} .(5)] \\
\lambda_{\text {Smith }}(\mathrm{W} / \mathrm{m} \mathrm{K})\end{array}$ & $\begin{array}{l}\text { Smith deviation } \% \\
\text { from measured } \lambda_{\mathrm{s}}\end{array}$ & $\begin{array}{l}\text { Base } \lambda_{\text {PLA }} \text { deviation } \\
\% \text { from measured } \lambda_{\mathrm{s}}\end{array}$ \\
\hline $\begin{array}{l}\text { CopperFill } \\
* \lambda_{\text {Copper }}=380 \\
(\mathrm{~W} / \mathrm{m} \mathrm{K})\end{array}$ & 0.4381 & 3.9904 & $(+) 160.42$ & 3.6657 & $(+) 157.29$ & $(+) 81.28$ \\
\hline $\begin{array}{l}\text { BronzeFill } \\
* \lambda_{\text {Bronze }}=50(\mathrm{~W} / \mathrm{m} \\
\mathrm{K})\end{array}$ & 0.5460 & 1.5677 & $(+) 96.67$ & 1.4957 & $(+) 93.03$ & $(+) 98.81$ \\
\hline $\begin{array}{l}\text { Magnetic iron } \\
\text { PLA } \\
* \lambda_{\text {Magnetic Iron }}=79.5 \\
(\mathrm{~W} / \mathrm{m} \mathrm{K})\end{array}$ & 0.2943 & 0.4271 & $(+) 36.82$ & 0.4114 & $(+) 33.18$ & $(+) 45.66$ \\
\hline $\begin{array}{l}\text { Stainless steel } \\
\text { PLA } \\
* \lambda_{\text {Stainless Steel }}=18 \\
(\mathrm{~W} / \mathrm{m} \mathrm{K})\end{array}$ & 0.3907 & 0.4106 & $(+) 4.98$ & 0.4074 & $(+) 4.17$ & $(+) 71.51$ \\
\hline Base PLA & 0.1849 & - & - & - & - & - \\
\hline
\end{tabular}

*means reference values

of air void fraction between each printed metal/polymer composite layer. Optimized printing parameters, specifically extrusion temperature $\left({ }^{\circ} \mathrm{C}\right)$ and speed $(\mathrm{mm} / \mathrm{s})$, could alleviate this issue To investigate the proposed theory, secondary calculation utilizing the prescribed through plane and non-continuous heat flow path assumptions, thermal conductivity values are equated. Table 8 represents these determinations abiding Eq. (3) (Lichtenecker dependence) has been applied to determine the perpendicular (relative to the printed layer) thermal conductivity of the composite. The determined composite(s) thermal conductivity (Table 6) are re-utilized as an input into Eq. (3) to 
Table 7 Smith air void correction vs. Landauer air void correction

\begin{tabular}{lllll}
\hline Sample material & $\begin{array}{l}\text { Average holometrix TCA } \\
300 \lambda_{\mathrm{s}}(\mathrm{W} / \mathrm{m} \mathrm{K})(\text { Table } 6)\end{array}$ & $\begin{array}{l}\text { Smith air void correction } \\
{[\mathrm{Eq} .(5)] \lambda_{\text {Smith }}(\mathrm{W} / \mathrm{m} \mathrm{K})}\end{array}$ & $\begin{array}{l}\text { Landauer air void correction } \\
{\left[\text { Eq. (8)] } \lambda_{\text {Landauer }}(\mathrm{W} / \mathrm{m} \mathrm{K})\right.}\end{array}$ & $\begin{array}{l}\text { Percent variance Smith method } \\
{[\text { Eq. (5)] vs. Landauer method }} \\
{[\text { Eq. (8)] }}\end{array}$ \\
\hline CopperFill & 0.4381 & 3.6657 & 3.6565 & $(-) 0.25$ \\
BronzeFill & 0.5460 & 1.4957 & 1.4945 & $(-) 0.08$ \\
Magnetic iron PLA & 0.2943 & 0.4114 & 0.4112 & $(-) 0.05$ \\
Stainless steel PLA & 0.3907 & 0.4074 & 0.3976 & $(-) 2.43$ \\
\hline
\end{tabular}

Table 8 Lichtenecker through plane air layer thermal conductivity determination

\begin{tabular}{llll}
\hline Filament & $\begin{array}{l}\text { Lichtenecker prediction } \\
{\left[\text { Eq. (3)] } \begin{array}{l}\lambda_{\text {Lichtenecker }}(W / m \\
\text { K) }\end{array}\right.}\end{array}$ & $\begin{array}{l}\text { Air void vol- } \\
\text { ume fraction } \%\end{array}$ & $\begin{array}{l}\text { Lichtenecker through plane air layer } \\
\text { thermal conductivity } \lambda_{\text {LAYER }}(W / m \\
\text { K) }\end{array}$ \\
\hline CopperFill & 3.9904 & 5.63 & 3.02 \\
BronzeFill & 1.5677 & 3.19 & 1.37 \\
Magnetic iron PLA & 0.4271 & 2.75 & 0.39 \\
Stainless steel PLA & 0.4106 & 2.34 & 0.38 \\
\hline
\end{tabular}

determine the perpendicular thermal conductivity assuming that the air void fraction is a layer oriented perpendicular to the heat flow. Air void volume fraction percentages are utilized as shown in Table 5.

The variance between $\lambda_{\text {LAYER, }} \lambda_{\text {Lichtenecker, }} \lambda_{\text {Smith }}$ is most substantial in composites with $10^{3}$ or $10^{2}$ metallic thermal conductivity (W/m K). To obtain the measured Holometrix TCA 300 composite thermal conductivity of copperFill, bronzeFill, magnetic iron PLA and stainless steel PLA air void fraction percentages of 44.70, 26.31, 13.75 and $1.86 \%$, respectively, would be required. The performed Archimedes analysis suggest that these values are not representative of the composite matrix.

Single sample cross-sectional analysis is inadequate at quantifying the air void volume content. In effect, single sample microscopy of FFF developed samples do not represent the porosity of the entire matrix. Further analysis should aim for rigorous sample procedures to analyze all appropriate component locations and orientations. Methods utilized in these analysis analyzed the ZX plane for quantitative microscopy. A proposed method would utilize, at minimum, 3 distinct sample planes that highlight critical features of the XY, ZX and ZY three-dimensional coordinate planes. Figure 15 elaborates on this proposal.

Although all of the materials did not have high thermal conductivities expected of high weight percentage metal materials, there are several high-value applications of such 3-D printed materials that look metallic, but have low thermal conductivity. For example, these composites can be used in the fabrication of muntins for energy efficient windows with complex geometries. A muntin (also referred to

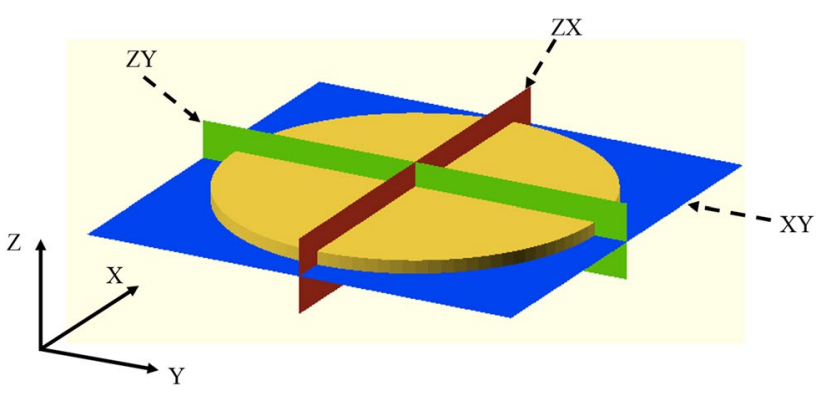

Fig. 15 Proposed cross-sectional analysis methods to properly quantify apparent air void fraction of FFF printed components

as muntin bar, glazing bar or sash bar) is generally a strip of metal separating and holding panes of glass in a window. Today, window manufacturers are basically locked into extruded shapes for muntins resulting in options of straight bars of slightly varying widths. 3-D printing composite materials such as those investigated here with high air void density would enable better heat retention in the building while enabling more artistic latitude and organic designs in windows. Future work is needed to test the UV stability of such composites, and high-temperature thermopolymers should also be investigated.

Limiting the printed component porosity by secondary processing methods needs to be investigated. Several processes are readily available and can potentially increase the printed density of the material. Specifically, isostatic pressing can be utilized post printing to increase layer to layer adhesion and remove residual air pockets as result of poor print vector overlap. Cold isostatic pressing (CIP) is readily 
applicable for this application. While immersed in a liquid, typically water based, isostatic pressure is applied to the specimen at an ambient temperature resulting in part densification. Initial investigations indicate a 5.0\% increase in printed density after a CIP operation. Samples subjected to experimentation had a similar geometry to the thermal conductivity samples. Components were subjected to vessel pressures of 30,000 psi and held for $5 \mathrm{~min}$, thus completing an entire test cycle. Significant dimensional variation (i.e., warp) resulted from the CIP processing. Conversely, hot isostatic pressing (HIP) utilizes the increase driving force of an elevated temperature to plastically deform internal cavities and promote diffusion bonding [38]. The melting temperature of PLA is greater than $155^{\circ} \mathrm{C}$ [39], while the typical HIP operating temperature range is $\sim 500-2000^{\circ} \mathrm{C}$ [38]. Thus, copperFill, bronzeFill, magnetic iron PLA and stainless steel PLA are not readily suited for this secondary process.

Considering the relative deviation from the filament raw bulk analysis, the printing operation significantly impacts the resultant component density. Baseline parameters sufficed for these analyses, however, future work should continue to develop the printing parameters for acquiring $100 \%$ density as printed. Elimination of required secondary processes, such as CIP, accelerates manufacturing time at reduced cost. As such, novel printing processes and procedures require development to optimize the current available systems. Obstacles to overcome, specific to complex build geometries, include both interior and exterior accommodations. External errors include: staircase/rastering effects, cure approximation errors, top/bottom skins and start-stop errors [34]. Internal errors, more directly effecting throughthickness thermal conductivity measurements, include: proper alignment of contour and internal vector path overlap resulting in air voids, inadequate material flow during material deposition processes [34].

Metal polymer filament composites, as described in these analysis, have a limited supply on the open market. Few manufactures readily develop composite filament materials for thermal applications. Numerous investigations have developed understandings of electrically conductive polymers suited for FFF [40, 41]. However, thermal applications specific to thermal conductivity are limited at this time. Custom manufactured filaments utilizing semi-automated recyclebot technology [42] can be investigated, which can use post-consumer thermoplastics [43]. Design of the recyclebot technology is feasible to suggest the potential application to the material development of composite materials. A proof of concept, in this realm, could yield vast advancements in polymer and powdered metal recycling capabilities. Specific to the industrial 3-D printing/additive manufacturing sphere, powdered metal is readily available as a waste product.
Generally, the nominal particle size of the metallic powder deviation and the smooth sphere morphology is distorted as result of continual re-use [44]. The deviated particle will begin to degrade the mechanical performance of the printed components. Large particles sizes typically result in porosity and edge contour gaps relative to the internal microstructure. Thus, un-useable powdered materials could be combined with recycled plastic filament to yield recycled metal polymer composites for 3-D printing.

\section{Conclusions}

Porosity coupled with lack of sufficient metal constituent cross section resulted in degraded thermal conductivity performance. Current manufacturing and secondary processing techniques have shown to increase the thermal conductivity of the matrix of copperFill, bronzeFill, magnetic iron PLA and stainless steel PLA by 81.28 , 98.81, 45.66 and $71.51 \%$, respectively. While non-ideal results have surmounted after rigorous analysis, a proof of concept has been proposed. However, further work is required to maximize the metallic filler volume percent and thus increase available sites for thermal transfer. Using recyclable metal powder materials, recylebot technologies aim to develop custom composite materials with various metallic filler volume percentages. Also, quantitative volume fraction determination requires further advancement, including appropriate model fittings. The utilized thermodynamic models do not properly model an FFF printed sample polylactic acid-metal composite in their current state. Future work is needed to properly represent the irregular air void fraction shape, layer to layer interface mechanisms, and percolation site probability/ random dispersion of metallic powder. Secondary processing mechanisms, specifically CIP, have been shown to be capable of decreasing printed matrix porosity. Further CIP development needs to occur to reduce the geometric shift (i.e., warp during the process).

Acknowledgments The authors would like to acknowledge technical assistance from G. Anzalone and P. Fraley and support from Aleph Objects, Inc. and the ARPA-E ARID program.

\section{References}

1. Sells E, Smith Z, Bailard S, Bowyer A, Olliver V (2010) RepRap: the replicating rapid prototyper: maximizing customizability by breeding the means of production. Handbook of Research in Mass Customization and Personalization, Forthcoming 
2. Jones R, Haufe P, Sells E, Iravani P, Olliver V, Palmer C, Bowyer A (2011) RepRap-the replicating rapid prototyper. Robotica 29(01) 177-191. doi:10.1017/S026357471000069X

3. Bowyer A (2014) 3D printing and humanity's first imperfect replicator. 3D Print Addit Manuf 1(1):4-5. doi:10.1089/ 3dp. 2013.0003

4. Rundle G (2014) A revolution in the making. Affirm Press, South Melbourne

5. Moilanen J, Vadén T (2012) Manufacturing in motion: first survey on 3D printing community. Stat Stud Peer Prod 1:6

6. Irwin JL, Oppliger DE, Pearce JM, Anzalone G (2015) Evaluation of RepRap 3D Printer Workshops in K-12 STEM. 122nd ASEE 122nd ASEE Conf. Proceedings. Paper ID\#12036, 2015

7. Gebler M, Uiterkamp AJS, Visser C (2014) A global sustainability perspective on $3 \mathrm{D}$ printing technologies. Energy Policy 74:158-167. doi:10.1016/j.enpol.2014.08.033

8. Pearce JM, Blair CM, Laciak KJ, Andrews R, Nosrat A, Zelenika-Zovko I (2010) 3-D printing of open source appropriate technologies for self-directed sustainable development. J Sustain Dev 3(4): 17

9. Lipson H, Kurman M (2013). Fabricated: the new world of 3D printing. Wiley, New Jersey

10. Berman B (2012) 3-D printing: the new industrial revolution. Business horizons 55(2):155-162. doi:10.1016/j. bushor.2011.11.003

11. Laplume A, Anzalone GC, Pearce JM (2016) Open-source, self-replicating 3-D printer factory for small-business manufacturing. Int J Adv Manuf Technol 85(1):633-642. doi:10.1007/s00170-015-7970-9

12. Masood SH, Song WQ (2004) Development of new metal/polymer materials for rapid tooling using fused deposition modeling. Mat Des 7:587-694. doi:10.1016/j.matdes.2004.02.009

13. Hopkinson N, Dicknes P (2003) Analysis of rapid manufacturing-using layer manufacturing processes for production. Proceedings of the Institution of Mechanical Engineers, Part C. J Mech Eng Sci 217(1):31-39. doi:10.1243/095440603762554596

14. Wittbrodt BT, Glover AG, Laureto J, Anzalone GC, Oppliger D, Irwin JL, Pearce JM (2013) Life-cycle economic analysis of distributed manufacturing with open-source 3-D printers. Mechatronics 23(6):713-726. doi:10.1016/j. mechatronics.2013.06.002

15. Kreiger M, Pearce JM (2013) Environmental life cycle analysis of distributed three-dimensional printing and conventional manufacturing of polymer products. ACS Sustain Chem Eng 1(12):1511-1519. doi:10.1021/sc400093k

16. Sa'ude N, Masood SH, Nikzad M, Ibrahim M, Ibrahim MHI (2013) Dynamic mechanical properties of copper-ABS- composite for FDM feedstock. Int J Eng Res Appl 3(3):257-1263. (http://citeseerx.ist.psu.edu/viewdoc/download?doi=10.1.1.41 $8.8269 \&$ rep $=$ rep $1 \&$ type $=$ pdf)

17. Wu G, Langrana NA, Sadanji R, Danforth S (2002) Solid freeform fabrication of metals components using fused deposition of metals. Mat Des 23(1):97-105. doi:10.1016/ S0261-3069(01)00079-6

18. Lee GW, Park M, Kim J, Lee JI, Yoon HG (2006). Enhanced thermal conductivity of polymer composites filled with hybrid filler. Compos Part A Appl Sci Manuf 37(5):727-734. doi:10.1016/j.compositesa.2005.07.006

19. Wilson JL, Poddar P, Frey NA, Srikanth H, Mohomed K, Harmon JP, Kotha S, Wachsmuth J (2004) Synthesis and magnetic properties of polymer nanocomposites with embedded iron nanoparticles. J Appl Phys 95(3):1439-1443. doi:10.1063/1.1637705

20. Hoque MJ, Chakraborty S, Mahbub M, Gafur MA (2013) Thermal conductivity of polypropylene based composite materials filled with graphite and carbon black. Int J Compos Mat 3:5. doi:10.5923/j.cmaterials.20130305.04
21. Tekce HS, Kumlutas D, Tavman IH (2007) Effect of particle shape on thermal conductivity of copper reinforced polymer composites. J Reinf Plast Compos 26(1):113-121. doi:10.1177/0731684407072522

22. Technical Datasheet copperFill (Eng)-ColorFabb (2016) http:// www.colorfabb.com/files/TDS-copperFill-en.pdf. Accessed 24 Jan 2016

23. Technical Datasheet bronzeFill-ColorFabb (2016) http://www. colorfabb.com/files/TDS-bronzeFill-en-.pdf. Accessed 24 Jan 2016

24. Proto-pasta (2016) "Stainless Steel PLA". http://www.protopasta.com/pages/stainless-steel-pla. Accessed 24 Jan 2016

25. Proto-pasta (2016) "Magnetic Iron PLA". http://www.protopasta.com/pages/magnetic-iron-pla. Accessed 24 Jan 2016

26. "Evaluating Thermal Conductivity of Gasket Materials" (2014) ASTM Test Method F433-02 (Reapproved 2014)

27. Tymrak BM, Kreiger M, Pearce JM (2014) Mechanical properties of components fabricated with open-source 3-D printers under realistic environmental conditions. Mat Des 58:242-246. doi:10.1016/j.matdes.2014.02.038

28. Wittbrodt B, Pearce JM (2015) The effects of PLA color on material properties of 3-D printed components. Addit Manuf 8:110-116. doi:10.1016/j.addma.2015.09.006

29. Rasband WS (2017) ImageJ, U.S. National Institutes of Health, Bethesda, Maryland, USA. http://imagej.nih.gov/ij/

30. Operating Instructions (2016) "Mettler Toledo $33360+210260$ Density determination kit". Accessed 24 Jan 2016

31. Product Information (2015) "Dow Corning ${ }^{\circledR} 340$ Heat Sink Compound TDS". Available from: http://www.dowcorning.com/ DataFiles/090276fe801904dc.pdf. Accessed 9 May 2015

32. King JA, Johnson BA, Via MD, Ciarkowski CJ (2010) Effects of carbon fillers in thermally conductive polypropylene based resins. Polym Compos 31(3):497-506. doi:10.1002/pc.20830

33. Mamunya YP, Davydenko VV, Pissis P, Lebedev EV (2002) Electrical and thermal conductivity of polymers filled with metal powders. Eur Polym J 38(9):1887-1897. doi:10.1016/ S0014-3057(02)00064-2

34. Agarwala MK, Jamalabad VR, Langrana NA, Safari A, Whalen PJ, Danforth SC (1996) Structural quality of parts processed by fused deposition. Rapid Prototyp J 2(4):4-19. doi:10.1108/13552549610732034

35. Smith DS, Alzina A, Bourret J, Nait-Ali B, Pennec F, TessierDoyen N, Otsu K, Matsubara H, Pierre E, Gozenbach UT (2013) Thermal conductivity of porous materials. J Mater Res 28(17):2260-2272. doi:10.1557/jmr.2013.179

36. Landauer R (1952) The electrical resistance of binary metallic mixtures. J Appl Phys 23(7):779-784

37. Tsotsas E, Martin H (1987) Thermal conductivity of packed beds: a review. Chem Eng Process Process Intensif 22(1):19-37. doi:10.1016/0255-2701(87)80025-9

38. Atkinson HV, Davies S (2000) Fundamental aspects of hot isostatic pressing: an overview. Metall Mat Trans A 31(12):29813000. doi:10.1007/s11661-000-0078-2

39. Technical data sheet Bio-Flex-ColorFabb (2016) Available from: http://www.colorfabb.com/files/FKUR/TD_BIOFLEX_V_135001_en.pdf. Accessed 24 Jan 2016

40. Czyżewski J, Burzyński P, Gaweł K, Meisner J (2009) Rapid prototyping of electrically conductive components using $3 \mathrm{D}$ printing technology. J Mater Process Technol 209(12):52815285. doi:10.1016/j.jmatprotec.2009.03.015

41. Leigh SJ, Bradley RJ, Purssell CP, Billson DR, Hutchins DA (2012) A simple, low-cost conductive composite material for 3D printing of electronic sensors. PloS One 7(11):e49365. doi:10.1371/journal.pone.0049365 
42. Baechler C, DeVuono M, Pearce JM (2013) Distributed recycling of waste polymer into RepRap feedstock. Rapid Prototyp J 19(2):118-125. doi:10.1108/13552541311302978

43. Hunt EJ, Zhang C, Anzalone N, Pearce JM (2015) Polymer recycling codes for distributed manufacturing with 3-D printers. Res Conserv Recycl 97:24-30. doi:10.1016/j.resconrec.2015.02.004
44. Tang HP, Qian M, Liu N, Zhang XZ, Yang GY, Wang J (2015) Effect of powder reuse times on additive manufacturing of Ti-6Al-4V by selective electron beam melting. Jom 67(3):555563. doi:10.1007/s11837-015-1300-4 